\title{
ANALYSIS OF THE COUPLING BETWEEN RECTANGULAR MICROSTRIP PATCHES ON UNIAXIAL ANISOTROPIC SUBSTRATES
}

\author{
José de R. S. Oliveira \\ Centro Federal de Educação Tecnológica do Maranhão \\ Diretoria de Ensino - Departamento de Eletro-Eletrônica \\ Caixa Postal 1533 - UFRN 59072-970 Natal, RN, Brasil Fax: (083) 333-2480 \\ Adaildo G. d'Assunção \\ Universidade Federal do Rio Grande do Norte \\ Centro e Tecnologia - Departamento de Engenharia Elétrica \\ Caixa Postal 1655 - UFRN - 59072-970 Natal, RN, Brasil Fax: (083) 231-9048 \\ Creso S. da Rocha \\ Universidade Federal da Paraíba \\ Centro de Ciências e Tecnologia - Departamento de Engenharia Elétrica \\ 58109-970 Campina Grande, PB, Brasil Fax: (083) 333-2480
}

\begin{abstract}
Resumo: O efeito da anisotropia dielétrica no comportamento das frequências ressonantes de antenas de microfita acopladas é investigado. $\mathrm{Na}$ análise, a técnica dos potenciais vetoriais de Hertz, no domínio espectral, é usada para determinar as expressões dos componentes dos campos, enquanto o método dos momentos (Galerkin) é usado para resolver a equação matricial obtida pela imposição das condiçōes de contorno da estrutura em estudo. Os substratos das antenas de microfita são compostos por dois materiais dielétricos anisotrópicos uniaxiais. Os eixos ópticos nestas camadas dielétricas são orientados perpendicularmente ao plano-terra. Resultados numéricos são apresentados para a frequência de ressonância na geometria em análise. Foi observada excelente concordância com resultados disponíveis na literatura para antenas de microfita acopladas sobre substratos isotrópicos.
\end{abstract}

\begin{abstract}
The effect of the dielectric anisotropy in the behavior of the resonant frequencies of coupled microstrip patches is investigated. In the analysis, the Hertz vector potentials technique, in the spectral domain, is used to determine the field components expressions, while the moment (Galerkin ) method is used to solve the matrix equation obtained by imposing the boundary conditions of the structure under consideration. The microstrip patches substrates are composed by two uniaxial anisotropic dielectric materials. The optical axes in these dielectric layers are oriented perpendicularly to the ground plane. Numerical results are presented for the resonant frequency for the geometry under consideration. Excellent agreement was observed with results available in the literature for coupled microstrip patches on isotropic substrates.
\end{abstract}

Keywords: microstrip antennas, microstrip patches, resonant frequency, anisotropic materials

\section{INTRODUCTION}

In the last two decades, a growing interest in the analysis of microstrip resonators has been observed because of their application in the development of microstrip patch antennas [1]. The main advantages of the microstrip resonators, compared to the conventional ones, are: low weight and volume, and because they are easy to build and mount on plane and curved surfaces [2]-[3]. 
The first reported works in the literature were dedicated to the analysis of microstrip patches and resonators on isotropic dielectric substrates. Nevertheless, because of the fact that most of dielectric materials used in microwaves are anisotropic ones, the effect of the dielectric anisotropy has been considered by several authors [2]-[6].

By the way, results for microstrip patches on planar structures with magnetized ferrimagnetic substrates are available in the literature [3], [7], [8].

Furthermore, the study of planar coupled resonators on anisotropic substrates has been considered by several authors for both suspended stripline [9] and microstrip [10] resonators, to determine the structure resonant frequency.

In this work,results for the resonant frequency of coupled microstrip patches, mounted over two different anisotropic dielectric layers are presented, as well as the effect of the dielectric anisotropy in the resonant structure performance (Fig.1).

In the analysis for the resonant frequency of a single microstrip patch, the Hertz potentials theory, in the spectral domain, in combination with the moment method is used. For the case of coupled microstrip patches, the analysis is performed by considering the even and odd modes theory, taking advantage of the symmetry of the structure considered.

\section{THEORY}

The structure considered in this work is shown in Fig. 1. Regions 1 and 2 are anisotropic dielectric ones, being characterized by the electric permittivity tensor $\overline{\bar{\varepsilon}}_{j} \quad(j=1,2)$. Region 3 is air. The patches and the ground plane are perfectly conducting. The conducting patch thickness is neglected.

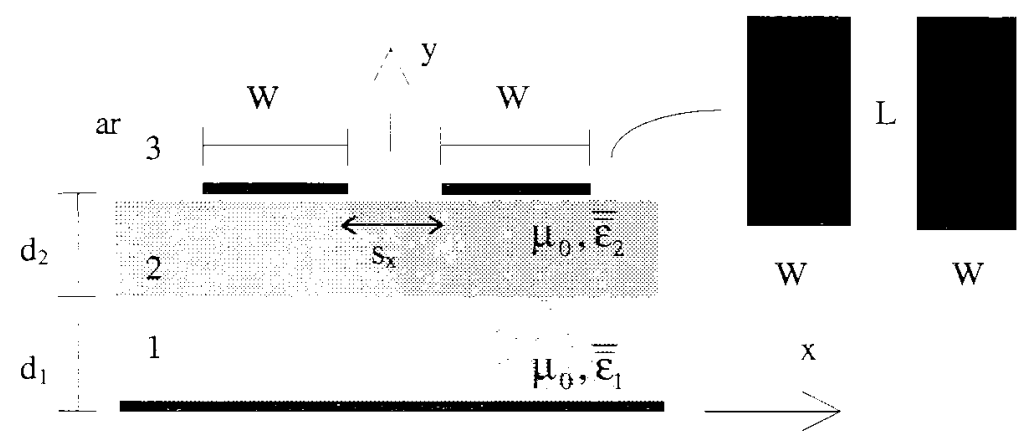

Fig. 1 - Coupled patches.

Since the optical axis of the anisotropic dielectric regions 1 and 2 are oriented along the y direction ( Fig, 1 ), their electric permittivities, $\overline{\bar{\varepsilon}}_{\mathrm{j}}(\mathrm{j}=1,2)$, are given by

$$
\varepsilon_{j}=\left[\begin{array}{ccc}
\varepsilon_{x x j} & 0 & 0 \\
0 & \varepsilon_{1 y j} & 0 \\
0 & 0 & \varepsilon_{x x y}
\end{array}\right] \cdot \varepsilon_{0} \quad(j=1,2)
$$

In this analysis, the determination of the resonant frequency of a single microstrip patch over two anisotropic layers is required. In order to do that, the Hertz vector potentials are defined to be along the optical direction ( $y$ in Fig. 1 ) according to

$$
\begin{aligned}
& \bar{\Pi}_{e}=\Pi_{e} \hat{a}_{y} \\
& \bar{\Pi}_{h}=\Pi_{h} \hat{\imath} y
\end{aligned}
$$

Then, the wave equations for $\bar{\Pi}_{\mathrm{e}}$ and $\bar{\Pi}_{\mathrm{h}}$ are obtained from Maxwell's equations, in the spectral domain, for each dielectric region in Fig. 1. The Fourier transformation is defined by [2]

$$
\tilde{\Psi}(\alpha, \beta)=\int_{-\infty}^{\infty} \int_{-\infty}^{\infty} \Psi(x, z) e^{j(\alpha x+\beta z)} d x(z-
$$




$$
\Psi(x, z)=\frac{1}{(2 \pi)^{2}} \int_{-\infty}^{\infty} \int_{-\infty}^{\infty} \tilde{\Psi}(\alpha, \beta) e^{-j(\alpha x+\beta z)} d \alpha d \beta
$$

where $\Psi(\mathrm{x}, \mathrm{z})$ is a generic function.

By using (4) and (5), the wave equations for $\widetilde{\Pi}_{\text {ej }}$ and $\widetilde{\Pi}_{h j}$ for dielectric region $j(j=1,2$ in Fig. 1$)$ are obtained as

$$
\begin{aligned}
& \frac{\partial^{2} \tilde{\Pi}_{e j}}{\partial v^{2}}-\gamma_{e j}{ }^{2} \widetilde{\Pi}_{e j}=0 \quad(\mathrm{j}=1,2) \\
& \frac{\partial^{2} \widetilde{\Pi}_{h j}}{\partial \eta^{2}}-\gamma_{h j}{ }^{2} \widetilde{\Pi}_{h j}=0 \quad(\mathrm{j}=1,2)
\end{aligned}
$$

respectively, where

$$
\begin{aligned}
& \gamma_{e j}^{2}=\frac{\varepsilon_{x x j}}{\varepsilon_{1 \eta j}}\left(\alpha^{2}+\beta^{2}-\omega^{2} \mu_{0} \varepsilon_{0} \varepsilon_{j 1}\right) \\
& \gamma_{h j}{ }^{2}=\alpha^{2}+\beta^{2}-\omega^{2} \mu_{0} \varepsilon_{0} \varepsilon_{\mathrm{j} 2}
\end{aligned}
$$

For region 3, which is filled with air, equations (6) to (9) remain valid, if $\varepsilon_{\mathrm{xx} 3}$ and $\varepsilon_{\mathrm{yy} 3}$ are set equal to 1 .

The electric and magnetic fields components, for dielectric region $\mathrm{j}(\mathrm{j}=1,2,3)$ are determined, in the spectral domain, from Maxwell's equations and are expressed by

$$
\begin{aligned}
& \tilde{E}_{x j}=\omega \mu_{0} \beta \tilde{\Pi}_{h j}-\frac{j \alpha}{\varepsilon_{x x j}} \frac{\partial \tilde{\Pi}_{e j}}{\partial y} \\
& \tilde{E}_{y j}=\omega^{2} \mu_{0} \varepsilon_{0} \tilde{\Pi}_{e j}+\frac{1}{\varepsilon_{x x j}} \frac{\partial^{2} \widetilde{\Pi}_{e j}}{\partial y^{2}} \\
& \tilde{E}_{z j}=-\omega \mu_{0} \alpha \tilde{\Pi}_{h j}-\frac{j \beta}{\varepsilon_{x x j}} \frac{\partial \tilde{\Pi}_{e j}}{\partial y} \\
& \tilde{H}_{x j}=-j \alpha \frac{\partial \tilde{\Pi}_{h j}}{\partial y}-\omega \varepsilon_{0} \beta \tilde{\Pi}_{e j} \\
& \tilde{H}_{y j}=\left(\alpha^{2}+\beta^{2}\right) \tilde{\Pi}_{h j} \\
& \tilde{H}_{z j}=-j \beta \frac{\partial \tilde{\Pi}_{h j}}{\partial y}+\omega \varepsilon_{0} \alpha \tilde{\Pi}_{e j}
\end{aligned}
$$

The solutions of the wave equations (6) and (7) are expressed, in a general form, as

$$
\begin{aligned}
& \tilde{\Pi}_{e j}=B_{j}(\alpha, \beta) \cosh \left(\gamma_{e j} \cdot{ }^{\prime}\right)+B_{j}^{\prime}(\alpha, \beta) \operatorname{senh}\left(\gamma_{e j} \cdot{ }^{l}\right) \\
& \tilde{\Pi}_{h j}=A_{j}(\alpha, \beta) \operatorname{senh}\left(\gamma_{h j}{ }^{1}\right)+L_{j}^{\prime}(\alpha, \beta) \cosh \left(\gamma_{h j} \cdot\right)
\end{aligned}
$$

respectively, for dielectric region $\mathrm{j}(\mathrm{j}=1,2)$. In dielectric region 3 , which is an open one, the expressions for $\widetilde{\Pi}_{\mathrm{e} 3}$ and $\tilde{\Pi}_{\mathrm{h} 3}$ are 


$$
\begin{aligned}
& \tilde{\Pi}_{e 3}=B_{3}(\alpha, \beta) e^{-\gamma_{0}\left(1-d_{1}-d_{2}\right)} \\
& \tilde{\Pi}_{h 3}=A_{3}(\alpha, \beta) e^{-\gamma_{0}\left(1-d_{1}-d_{2}\right)}
\end{aligned}
$$

respectively.

The unknown coefficients $A_{j}, B_{j}, A_{j}$ and $B_{j}{ }^{\prime}$ are determined by imposing the boundary conditions at the interfaces, for the electric and magnetic field components, which are:

$$
\begin{array}{ll}
\tilde{E}_{t 1}=0 & \text { em } \mathrm{y}=0 \\
\tilde{E}_{t 1}=\tilde{E}_{t 2} & \text { em } \mathrm{y}=\mathrm{d}_{1} \\
\tilde{H}_{t 1}=\tilde{H}_{t 2} & \text { em } \mathrm{y}=\mathrm{d}_{1} \\
\sim_{t 2}=\sim_{t 3} & \text { em } \mathrm{y}=\mathrm{d}_{12} \\
\tilde{H}_{z 3}-\tilde{H}_{z 2}=\tilde{J}_{x} & \text { em } \mathrm{y}=\mathrm{d}_{12} \\
\tilde{H}_{x 3}-\tilde{H}_{x 2}=-\tilde{J}_{z} & \text { em } \mathrm{y}=\mathrm{d}_{12}
\end{array}
$$

where the subscript " $t$ " means tangential components and $\widetilde{J}_{x}$ and $\widetilde{J}_{z}$ are the transformed current density components on the conducting patch.

After determining the expressions for $A_{j}, B_{j}, A_{j}$ and $B_{j}$, in dielectric region $j(j=1,2,3)$, the field components, in the Fourier domain, are obtained by using (10) to (15).

At the conducting patch plane, $y=d_{1}+d_{2}$, ( Fig. 1 ), the transformed electric field components, $\widetilde{\mathrm{E}}_{x}$ and $\widetilde{\mathrm{E}}_{z}$, are expressed as function of the transformed current density components, $\widetilde{\mathrm{J}}_{\mathrm{x}}$ and $\widetilde{\mathrm{J}}_{\mathrm{z}}$, as shown below

$$
\begin{aligned}
& \tilde{E}_{x}=\tilde{Z}_{x x} \tilde{J}_{x}+\tilde{Z}_{x z} \tilde{J}_{z} \\
& \tilde{E}_{z}=\tilde{Z}_{z x} \tilde{J}_{x}+\tilde{Z}_{z z} \tilde{J}_{z}
\end{aligned}
$$

where $\tilde{Z}_{x x}, \widetilde{Z}_{x z}, \widetilde{Z}_{z x}$ and $\widetilde{Z}_{z z}$ are the impedance matrix components, or dyadic Green's functions for the microstrip patch.

Once the impedance matrix $[\tilde{Z}]$ was obtained, the moment method (Galerkin) is used to determine the complex resonant frequency for the microstrip patch [2], [3].

In the moment method, the current density components $\widetilde{\mathrm{J}}_{\mathrm{x}}$ and $\widetilde{\mathrm{J}}_{\mathrm{z}}$ are expanded as a combination of basis functions, $\tilde{\mathrm{J}}_{\mathrm{xm}}$ and $\widetilde{\mathrm{J}}_{\mathrm{zm}}$, respectively, as

$$
\begin{aligned}
& \tilde{J}_{x}=\sum_{m=1}^{M} c_{m} \tilde{J}_{x m} \\
& \tilde{J}_{z}=\sum_{n=1}^{N} d_{n j}, \tilde{J}_{z n}
\end{aligned}
$$

where $c_{n}$ and $d_{n}$ are unknown constants.

By taking the scalar product of $(26)$ and $(27)$ by $\widetilde{J}_{x p}(p=1, \ldots, M)$ and $\widetilde{J}_{z q}(q=1, \ldots, N)$, respectively, one obtains

$$
\begin{aligned}
& \sum_{n} K_{m n}^{* x} c_{m}+\sum_{n} K_{p n}^{x} d_{n}=0 \quad \mathrm{p}=1, \ldots, \mathrm{M} \\
& \sum_{n} K_{m m}^{-x} c_{m}+\sum_{n} K_{m n}^{z} d_{n}=0 \quad \mathrm{q}=1, \ldots \mathrm{N}
\end{aligned}
$$

where 


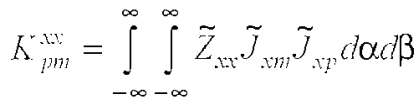

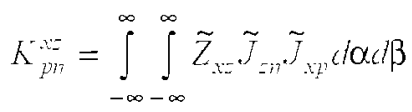

$$
\begin{aligned}
& K_{q m i}^{\alpha x}=\int_{-\infty}^{\infty} \int_{-\infty}^{\infty} \tilde{Z}_{x x} \tilde{J}_{x m} \tilde{J}_{z q} d \alpha d \beta \\
& K_{q u n}=\int_{-\infty}^{\infty} \int_{-\infty}^{\infty} \tilde{Z}_{z=} \tilde{J}_{z=n} \tilde{J}_{z q} d \alpha d \beta
\end{aligned}
$$

Non-trivial solutions for (30) and (31) are obtained by imposing $\operatorname{det}[\mathrm{K}]=0$, where the matrix $[\mathrm{K}]$ components are given by (32 to (35). The solutions for this equation are the resonant frequencies for the single microstrip patch.

To determine the resonant frequency for coupled microstrip patches ( Fig. 1 ), the electric current density components are expressed as functions of those considered in the analysis of a single microstrip patch, according to [10]

$$
\begin{aligned}
& \tilde{J}_{* i c}(\alpha, \beta)=\left[-\xi^{-j \alpha\left(s_{\lambda}+I I\right)}+e^{j \alpha\left(s_{1}+I I\right)}\right] \widetilde{J}_{*}(\alpha, \beta) \\
& \tilde{J}_{s c}(\alpha, \beta)=\left[\xi^{-j \alpha\left(s_{i}+i I^{\prime}\right)}+e^{j \alpha\left(s_{\lambda}+i I^{C}\right)}\right] \tilde{J}_{z}(\alpha, \beta)
\end{aligned}
$$

where $\xi=1$ for the even mode and $\xi=-1$ for the odd mode.

\section{RESULTS}

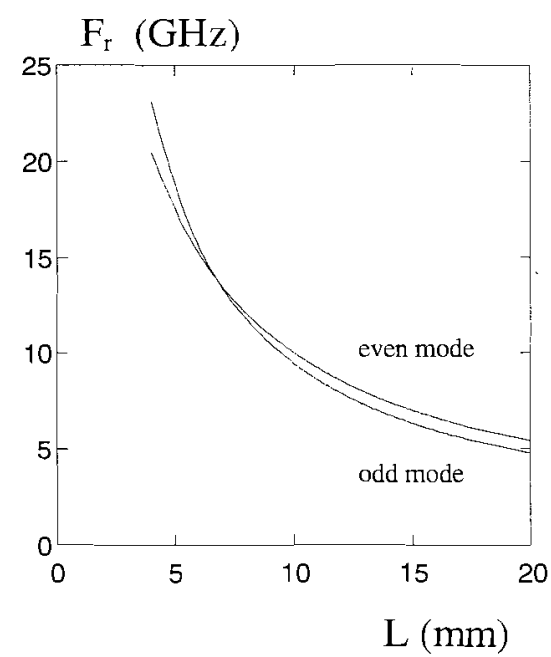

Fig. 2 - Resonant frequency versus patch length: $\mathrm{d}_{1}=0.1524 \mathrm{~cm}, \quad \mathrm{~d}_{2}=0.0508$ $\mathrm{cm}, \mathrm{w}=0,01 \mathrm{~cm}, \quad \mathrm{~s}_{\mathrm{x}}=0.02 \mathrm{~cm}, \varepsilon_{\mathrm{xx} 2}=$ $5.12, \varepsilon_{\mathrm{Y} Y 2}=3.4$ (boron nitride), $\varepsilon_{\mathrm{r} 1}=1,0$.

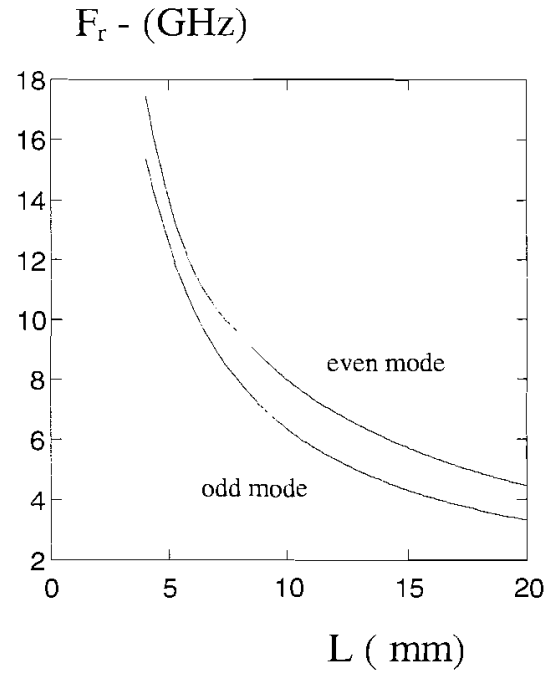

Fig. 3 - Resonant frequency versus patch length: $d_{1}=0.1524 \mathrm{~cm}, \quad d_{2}=0.0508$ $\mathrm{cm}, \mathrm{w}=0.01 \mathrm{~cm}, \quad \mathrm{~s}_{\mathrm{x}}=0.02 \mathrm{~cm}, \varepsilon_{\mathrm{x} \times 2}=$ 9.4, $\varepsilon_{\mathrm{yv} 2}=11.6 \quad$ (sapphire) $, \quad \varepsilon_{\mathrm{r} 1}=1,0$.

As it is shown in Fig. 2, for suspended coupled microstrip patches, the resonant frequencies for the even and odd modes decrease when the patch length, $L$, is increased. Note that an equalization is obtained at $L=6 \mathrm{~mm}$, or nearby. The structural parameters considered in the determination of the resonant frequencies are shown in Fig. 2. regions 1 and 3 are air-filled, while region 2 is filled with pyrolytic boron nitride (p.b.n)[2], for which $\varepsilon_{x \times 2}=5.12$ and $\varepsilon_{\mathrm{yy} 2}=3.4$.

In Fig. 3, the numerical results obtained for suspended coupled microstrip patches on sapphire $\left(\varepsilon_{x x 2}=9.4\right.$ e $\varepsilon_{y y 2}=11.6$ ) are shown [2]. Lower values for the resonant frequencies, for a given $\mathrm{L}$, are obtained in this structure compared to the one

using p.b.n (shown in Fig. 2 ), as expected. Note that there is no equalization between the even and odd mode results. Nevertheless, for low values of $\mathrm{L}$, from 4.0 to $5.0 \mathrm{~cm}$, the differences between the even and odd mode results are smaller. 
Fig. 4 shows the effect of the dielectric anisotropy ( in region 1 ) on the resonant frequency for single and coupled microstrip patches on a double layer. Dielectric region 2 is alumina filled $\left(\varepsilon_{\mathrm{r} 2}=9.6\right)$. The anisotropy ratio, $\mathrm{n}_{\mathrm{x}} / \mathrm{n}_{\mathrm{y}}($ for region 1 in Fig. 1 ), is given by

$\frac{n_{x}}{n_{y}}=\sqrt{\frac{\varepsilon_{x x}}{\varepsilon_{3 y}}}$

As it is shown in Fig. 4 , as $n_{x} / n_{y}$ increases, the resonant frequency increases for both single and coupled microstrip patches. It was observed that the results for both even and odd mode resonant frequencies approach the results for the resonant frequency of a single microstrip patch, when $s_{x} \rightarrow \infty$, as expected.

\section{$F_{\mathrm{r}}(\mathrm{GHz})$}

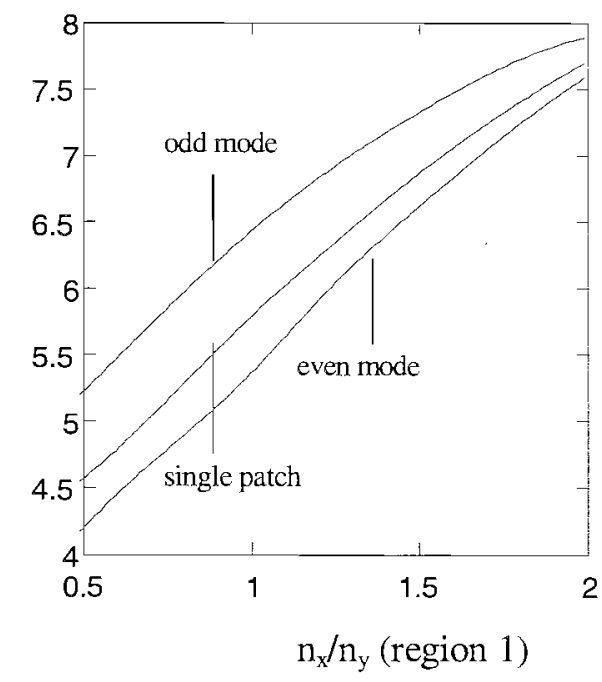

Fig. 4 - Resonant frequency versus anisotropy ratio: $\mathrm{d}_{1}=0.127 \mathrm{~cm}, \mathrm{~d}_{2}=0.0635$ $\mathrm{cm}, \mathrm{w}=0.4 \mathrm{~cm}, \mathrm{~L}=0.8 \mathrm{~cm}, \mathrm{~s}_{\mathrm{x}}=0.02 \mathrm{~cm}$, $\varepsilon_{\mathrm{xx} 1}=9.6, \varepsilon_{\mathrm{r} 2}=9.6$.

\section{$\mathrm{F}_{\mathrm{r}}(\mathrm{GHz})$}

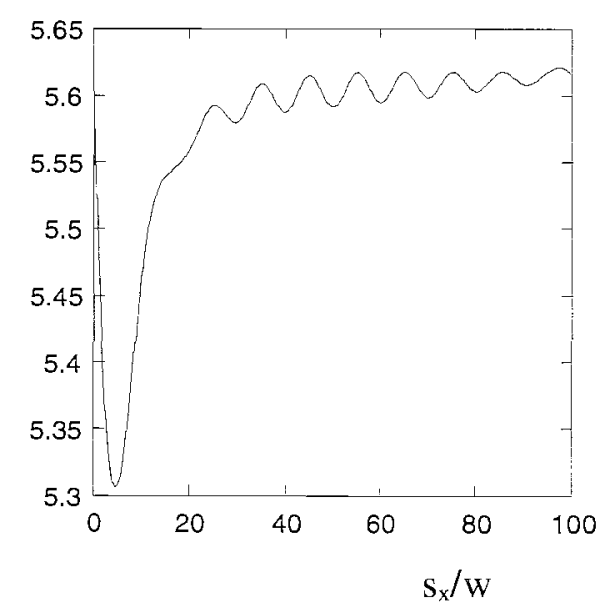

Fig. 6 - Resonant frequency versus versus $\mathrm{s}_{\mathrm{x}} / \mathrm{W}:{ }_{1}=0.0, \mathrm{~d}_{2}=0.0254 \mathrm{~cm}$, $\mathrm{w}=0.01 \mathrm{~cm}, \mathrm{~L}=1.0 \mathrm{~cm}, \varepsilon_{\mathrm{r} 2}=9.6$.

\section{$\mathrm{F}_{\mathrm{r}}(\mathrm{GHz})$}

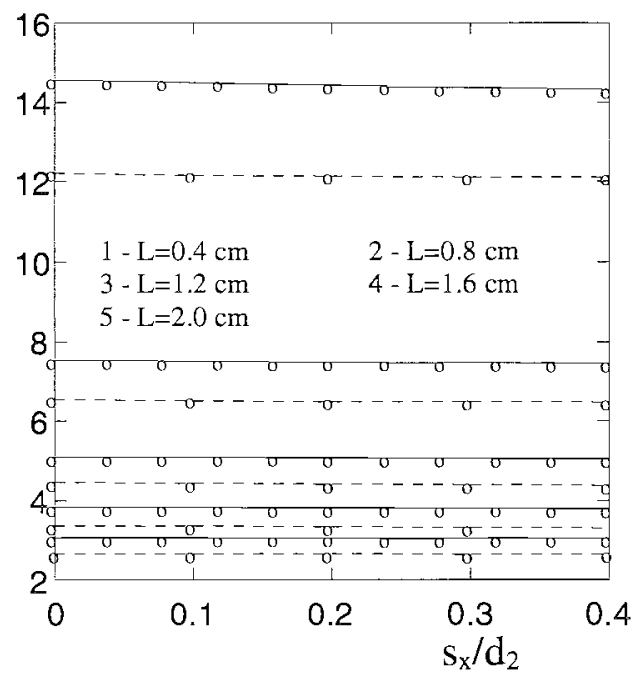

Fig. 5: Resonant frequency versus $s_{x} / d_{2}$ : $\mathrm{d}_{1}=0.0, \mathrm{~d}_{2}=0.0635 \mathrm{~cm}$, $\mathrm{w}=0.0635 \mathrm{~cm}, \varepsilon_{\mathrm{r} 2}=10.2$. (odd mode) SHARMA e BHAT [10] (even mode) SHARMA e BHAT [10] ooooo This work

\section{$\mathrm{F}_{\mathrm{r}}(\mathrm{GHz})$}

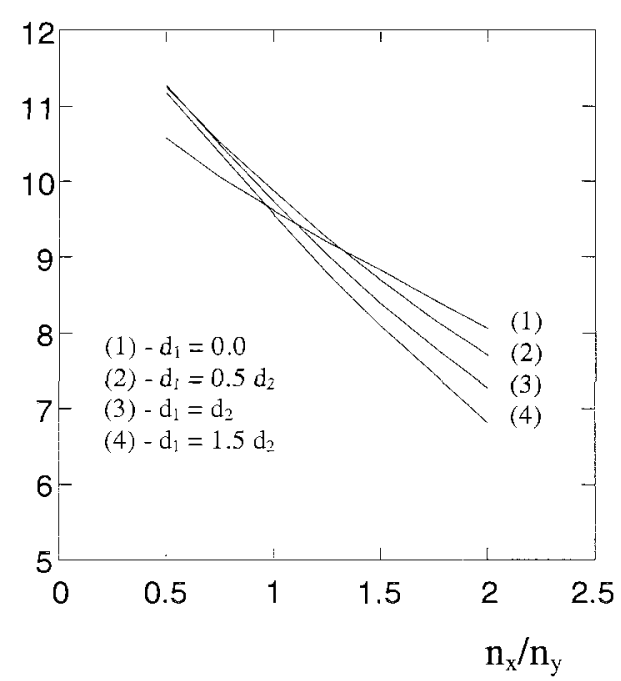

Fig. 7 - Resonant frequency versus $\mathrm{n}_{\mathrm{x}} / \mathrm{n}_{\mathrm{y}}$ : $\mathrm{W}=0.2 \mathrm{~cm}, \mathrm{~L}=1.0 \mathrm{~cm}, \mathrm{~d}_{2}=0.158 \mathrm{~cm}, \varepsilon_{\mathrm{yy} 2}=2.35$, $\varepsilon_{\mathrm{T} 1}=1.0$. 
A comparison between the results of this work ( $\mathrm{d}_{1}=0$ and $\varepsilon_{\mathrm{xx} 2}=\varepsilon_{\mathrm{yy} 2}=10.2$ ) with those available in the literature for coupled patches on a single isotropic layer $\left(\varepsilon_{\mathrm{r}}=10.2\right)$ [10] is presented in Fig. 5, showing an excellent agreement for the structural parameters considered. Different values of $\mathrm{L}$ were assumed.

Fig. 6 shows the behavior of the resonant frequency as function of the normalized spacing, $s_{x} / W$, (around 100), which is $F_{r}=5.61+j 0.0011 \mathrm{Ghz}$. Fig. 7 shows the resonant frequency versus the anisotropy ratio for coupled patchess on two '?vers, forr several values of $d_{1} / d_{2}$ (Fig. 1 ).

A comparison between the results of different techniques is shown in Tables I to IV, for single microstrip patch on isotropic and anisotropic substrates, respectively.A good agreement is observed.

\section{CONCLUSION}

The analysis and numerical results for the resonant frequencies of parallel coupled microstrip patches over anisotropic substrates was presented.

In the determination of the resonant frequency for a single microstrip patch (particular case ), the Hertz vector potential and the moment methods were used. A determinantal equation was obtained, which solutions are the complex resonant frequencies of the structure considered.

The resmant frequencies of parallel coupled microstrip patches was performed by using the even and odd mode theory. The clectric current density components for these modes were expressed as functions of that used in the analysis of a single patch.

A goxal agrecment between the results of this work and those available in the literature for the particular case of coupled patchi on a single isotropic dielectric layer was observed. The method presented here can be used to analyze other planar structurs including those with magnetized ferrimagnetic substrates

\begin{tabular}{|c|c|c|c|c|c|c|c|}
\hline 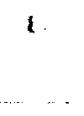 & $\mathrm{d}(\mathrm{cm})$ & $\mathrm{L}(\mathrm{cm})$ & $\mathrm{w}(\mathrm{cm})$ & measured & $\begin{array}{c}\text { cavity } \\
{[1]} \\
\end{array}$ & $\begin{array}{c}\text { moments } \\
{[11]} \\
\end{array}$ & $\begin{array}{l}\text { this } \\
\text { work }\end{array}$ \\
\hline $10 \%$ & 0.127 & 2.00 & 3.0 & 2.26 & 2.23 & 2.28 & 2.31 \\
\hline $111:$ & 11127 & 0.95 & 1.5 & 4.49 & 4.35 & 4.58 & 4.69 \\
\hline $101:$ & $1) .254$ & 1.90 & 3.0 & 2.24 & 2.18 & 2.29 & 2.35 \\
\hline 102 & 0.254 & 0.90 & 1.5 & 4.23 & 3.90 & 4.50 & 4.47 \\
\hline $2 \geq 2$ & 0.079 & 2.50 & 4.0 & 3.94 & 3.84 & 3.89 & 3.92 \\
\hline 2.22 & 0.079 & 1.25 & 2.0 & 7.65 & 7.42 & 7.61 & 7.66 \\
\hline 2.22 & 0.152 & 2.50 & 4.0 & 3.84 & 3.71 & 3.81 & 3.83 \\
\hline 2.22 & 0.152 & 1.20 & 2.0 & 7.72 & 7.12 & 7.55 & 7.63 \\
\hline
\end{tabular}

Tab. II - Resonant frequency - $\mathrm{d} 1=0.0, \mathrm{~d} 2=0.158 \mathrm{~cm}, \mathrm{~L}=1.0 \mathrm{~cm}, \varepsilon_{\mathrm{xx} 2}=9.4, \quad \varepsilon_{\mathrm{yy} 2}=2.35$.

\begin{tabular}{|c|c|c|}
\hline $\mathrm{w}(\mathrm{cm})$ & $\mathrm{F}_{\mathrm{r}}+\mathrm{j} \mathrm{F}_{\mathrm{i}}(\mathrm{GHz})$ & $\mathrm{F}_{\mathrm{r}}+\mathrm{j} \mathrm{F}_{\mathrm{i}}(\mathrm{GHz})[2]$ \\
\hline 1.5 & $7.718+\mathrm{j} 0.235$ & $7.773+\mathrm{j} 0.233$ \\
\hline 0.2 & $8.055+\mathrm{j} 0.091$ & $8.112+\mathrm{j} 0.112$ \\
\hline
\end{tabular}

Tab. III - Resonant frequency $-\mathrm{dl}=0.0, \mathrm{~d} 2=0.127 \mathrm{~cm}, \mathrm{~L}=0.6 \mathrm{~cm}, \mathrm{w}=0.4 \mathrm{~cm}, \varepsilon_{\mathrm{xx} 2}=9.6$.

\begin{tabular}{|c|c|c|}
\hline $\mathrm{nx} / \mathrm{ny}$ & $\mathrm{F}_{\mathrm{r}}+\mathrm{j} \mathrm{F}_{\mathrm{j}}(\mathrm{GHz})$ & $\mathrm{F}_{\mathrm{r}}(\mathrm{GHz})[2]$ \\
\hline 1 & $7.653+\mathrm{j} 0.029$ & 7.68 \\
\hline 2 & $12.135+\mathrm{j} 0.319$ & 12.19 \\
\hline
\end{tabular}


Tab. IV - Resonant frequency - $\mathrm{d} 1=1.651 \mathrm{~mm}, \mathrm{~d} 2=0.254 \mathrm{~mm}, \mathrm{~d} 3=0.0, \mathrm{~L}=0.4 \mathrm{~cm}, \mathrm{w}=0.1 \mathrm{~cm}, \varepsilon_{\mathrm{r} 1}=1.0, \varepsilon_{\mathrm{yy} 2}=9.6$.

\begin{tabular}{|c|c|c|}
\hline $\mathrm{nx} / \mathrm{ny}$ & $\mathrm{F}_{\mathrm{r}}+\mathrm{jF} \mathrm{F}_{\mathrm{i}}(\mathrm{GHz})$ & $\mathrm{Fr}(\mathrm{GHz})[2]$ \\
\hline 1 & $17.845+\mathrm{j} 1.419$ & 17.77 \\
\hline 2 & $10.995+\mathrm{j} 0.734$ & 10.95 \\
\hline
\end{tabular}

\section{REFERENCES}

[1] Y. T. LO, D. SOLOMON e W. F. RICHARDS, "Theory and experiment on microstrip antennas", IELE: Trans. Antennas Propagat., v. AP-27, n. 2, p. 137-145, March 1979.

[2] R.M. NELSON, D.A. ROGERS e A.G. D'ASSUNÇÃO, "Resonant frequency of a rectangular microstrip patch on several uniaxial substrates", IEEE Trans. Antemas: Propagal., v. AP-38, n. 7, p. 973-981, July 1990.

[3] A.G. D'ASSUNÇÃO e E.J.A. DANTAS, "On the resonant frequency of magnetized rectangular microstrip patch resonators", IEEE tP-S Antennas Propagation Simp., Ann Arbor, MI, p. 1508-1511, June 1993.

[4] T. ITOH, "A full-wave analysis method for open microstrip structures", IEEE Trans. .Intennas Propagat., v. AP29, n. 1, p.63-67, January 1981.

[5] K.-L. WONG, J.-S. ROW, C.-W. KUO e K.-C. HUANG, "Resonance of a rectangular patch on a uniaxial substrate", IEEE Trans. Gicrowave Theory' Tech., vol. 41, n. 4, p. 698-701, April 1993.

[6] D.M.POZAR, "Radiation and scattering from a microstrip patch on a uniaxial substrate", IEEE Trans. Antennas Propagation, v. AP-35, n.6, p.613-621, June 1987.

[7] D.M.POZAR, "Radiation and scattering characteristic of microstrip antennas on normally biased ferrite substrates", IEEE Trans. Antenna Propagat., AP-40, n.9, p. 1084-1092, September 1992.

[8] H.-Y. YANG, J.A. CASTANHEDA and G. ALEXOUPOLOS, "The RCS of a microstrip patch on an arbitrarily biased ferrite substrate", IEEF Trans. Intennas Propagat., AP-41, No. 12, pp. 1610-1614, December 1993.

[9] R. KHANNA, S. K. KOUL e B. BHAT, "Characteristics of single and coupled rectangular resonators in suspended substrate stripline", Electronics Letters, v. 22, n. 7, pp. 376-378 March 1986.

[10] A. K. SHARMA e B. BHAT, "Spectral domain analysis of interacting microstrip resonant structures", IEEE. Trans. Microwave Theory Tech., v. MTT-31, n. 8, pp. 681-687, August 1983.

[11] D. M. POZAR, "Imput impedance and mutual coupling of rectangular microstrip antenna", IEEE Trans. Antennas Propagat., v. AP-30, n. 6, p. 1191-1196., november 1982.

Adaildo Gromes d'Assunção received the B. S. E. E. degree ( with honors ) from the Federal University of Rio Grande do Norte, RN, Brazil, in 1974, and the M. S. and doctoral degree in electrical engineering from the State University of Campinas, SP, Brazil, in 1977 and 1981, respectively.From 1975-1976, he worked with radar and telemetry systems at the Launching Center of Barreira do Inferno, Natal, RN, Brazil. He has been with the Federal University of Rio Grande do Norte since 1976, where he is an Associate Professor of Electrical and Electronics Engineering. From 1985-1987, he was a Postdoctoral Visiting Scientist in the Department of Electrical and Electronics Engineering at North Dakota State University, Fargo. He is currently teaching and conducting research on antennas microwave integrated circuits and millimeter waves.Dr. d'Assunção is a member of the Brazilian Microwave and Optoelectronics Society (SBMO) and of the Brazilian Telecommunication Society (SBT).

José de Ribamar Silva Oliveira received the B. S. E. E. degree from the Federal University of Maranhão, in 1980, and the M. S. E. E. degree from the Federal University of Rio Grande do Norte, in 1990. He has been with the Federal Center of Technological Education of Maranhão since 1983 where he is a professor of Electronics and Electricity. He is currently working toward a Ph. D. degree at the Federal University of Paraiba, in Campina Grande, Brazil, working in the areas of microstrip antennas and transmission lines. He is a member of the Brazilian Telecommunications Society ( SBT ) and of the Brazilian Microwave and Optoelectronics Society ( SBMO ). He is also a member of the IEEE Microwaves Theory and Technique and Antennas and Propagation Societies.

Creso Santos da Rocha received the B.S.E.E. and the M.S.E.E degrees from the Federal University of Paraiba en 1969 and 1972, respectively. His Ph. D. degree was obtained from the University of Waterloo in 1979. In 1970 he joined the Federal University of Paraiba, where he is currently an associate professor. His research interests are in microwaves, antennas, open waveguides and numerical methods. He is a member of the Brazilian Microwave and Optoelectronics Society ( SBMO) and of the Brazilian Telecommunication Society ( SBT) 